\title{
Rationally Designed Ag@polymer@2-D LDH Nanoflakes for Bifunctional Efficient Electrochemical Sensing of 4-Nitrophenol and Water Oxidation Reaction
}

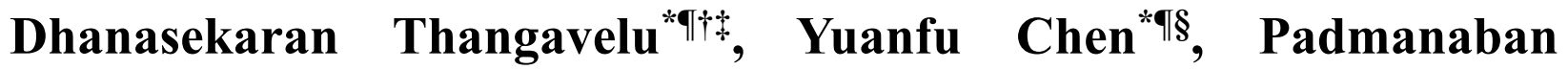 Annamalai $i^{\sharp}$ Manigandan Ramadoss ${ }^{\star \pi}$, and Vengidusamy Narayanan}

"School of Electronic Science and Engineering, and State Key Laboratory of Electronic T hin Films and Integrated Devices, University of Electronic Science and Technology of China, Chengdu 610054, PR China

+ School of Chemistry, U niversity of $\mathrm{H}$ yderabad, $\mathrm{H}$ yderabad 500046 , India

*D epartment of I norganic C hemistry, U niversity of M adras, C hennai 600025, India

${ }^{\S}$ School of Science, and Institute of O xygen Supply, T ibet U niversity, Lhasa 850000, PR China

*Email: yfchen@uestc.edu.cn (Yuanfu C hen), dhana06che35@gmail.com;_dhana_pdf@uohyd.ac.in; ( D hanasekaran Thangavelu)

\section{Additional Experimental Details, Materials and Methods:}

X-ray photoelectron spectroscopy (XPS) data were recorded at Omicron Nanotechnology, ESCA (Germany), equipped with a hemispherical analyzer. The purity of the crystal phase was measured by powder diffraction method, Seifert X-ray diffractometer by $\mathrm{Cu} \mathrm{k}_{\alpha 1}$ radiation $(\lambda=$ $1.5406 \AA$ ) for the prepared sample. FT-IR was used to determine the stretching vibration of the catalyst present in the compounds using Shimadzu FT-IR 8300, ranging from $4000 \mathrm{~cm}^{-1}-400 \mathrm{~cm}^{-}$

${ }^{1}$ ( $\mathrm{KBr}$ pellet mode). Electronic absorption spectra of the samples recorded using (UV-vis DR spectra) Perkin Elmer lambda 650 spectrophotometer (Range $200 \mathrm{~nm}-800 \mathrm{~nm}$ ). The structural vibration of the sample stretching was analyzed from the Confocal Raman Spectroscopy record by using BRUKER RFS-27. BET analysis carried out using Autosorb-iQ surface area and pore size analyzer instruments. Thermal analysis of the prepared samples carried out by alumina protected (SDT Q600) underflow of UHP nitrogen or argon gas (flow rate $=100 \mathrm{~cm}^{3} \mathrm{~min}^{-1}$ ). Morphological studies obtained from field emission scanning electron microscope (FESEM) adopted with energy dispersive X-ray (EDX) by Carl Zeiss model Merlin compact equipped with an Oxford instrument 
(X-MaxN SDD $\left(\mathrm{mm}^{2}\right)$. FEI TECNAI G2 S-Twin TEM carried out high-resolution transmission electron microscopy used for related structural information at an accelerating voltage of $200 \mathrm{kV}$. Carbon coated grids 200 Mesh Type-B were purchased from Ted Pella Inc. USA. The electrochemical sensing experiments were done by using CHI 1103A electrochemical workstation using a 3-electrode system. Pt wire and saturated calomel electrode (SCE) act as the counter and reference electrode for the 4-Np to 4-Ap conversion. Further, the modified glassy carbon electrode (GCE) is a working electrode. The Saturated calomel, platinum wire, and Glassy carbon serve as a reference, counter, and working electrode.

\section{Hollow Sphere Formation Mechanism}

The hollow morphology formation process is due to the "falling $\mathrm{pH}$ " method for generating hollows in the polymers. The different types of acid/bases phenomenon appear to be quite general, which concern the solution's $\mathrm{pH}$ to the formation of the hollow spheres. So, when using the $\mathrm{AgNO}_{3}$ precursor's solution, $\mathrm{NO}_{3}{ }^{-}$ions easily replace the other ligands. The $\mathrm{e}^{-}$rich $\mathrm{N}$-contains in the orthophenylenediamine (o-PD) are electrostatically attracted with e- deficient behaviors of the $\mathrm{Ag}^{+}$ ions. Finally, $\mathrm{Ag}$ NPs grown on the PoPD/LDH surfaces due to the continuous reduction of $\mathrm{Ag}^{+}$ to the Ag NPs.

Nonetheless, the morphology is determined by the "self-assembly" method. The selforganized of the monomers micelles present at the initial reaction stages. They act as patterns in the formation of hollow spheres, and polymerization occurs at the micelle/ $\mathrm{H}_{2} \mathrm{O}$ interface in the presence of a hydrophilic ammonium persulfate (APS) oxidizer. Aggregation and fusion into the larger spheres occur. During the polymerization, the monomers contained in the inner space of the micelle are difficult to the surface leading to the formation of hollow spheres. However, hollow spheres growing by the diffusion of water component into the depth probably favors the formation 
process. Also, several different techniques are available for synthesizing hollow spheres and spheres, such as the hydrothermal method in different conditions [1,2].

\section{TGA Analysis}

Thermogravimetry analysis performed in the region of $800{ }^{\circ} \mathrm{C}$, the obtained information could exist the stability of the nanohybrid materials. Figure S1 (supporting information) Ni-Al LDH (black line) has three mass loss features on the TGA curve, decomposition stages with three corresponding endothermic processes attributed to the removal of adsorbed water from surface and interlayer below $200{ }^{\circ} \mathrm{C}$, dehydroxylation $\left(\mathrm{OH}^{-}\right)$of hydrotalcite layer at $340{ }^{\circ} \mathrm{C}$ and weight loss of interlayer anions at a higher temperature. In contrast, the weight loss percentage was approximately 10\% and 20\%, respectively. Polymer@LDH (red line) and Ag@polymer/LDH (blue line) indicate the TGA curve for Ag and polymer composites of nanohybrid, the stability of materials enhanced due to composite of Ag NPs and polymer because weight loss gradually decreased. However, the major two weight loss obtained to polymer@LDH and $\mathrm{Ag} @$ polymer/LDHs and mass loss percentage is about $15 \%$ and $18 \%$, respectively. 


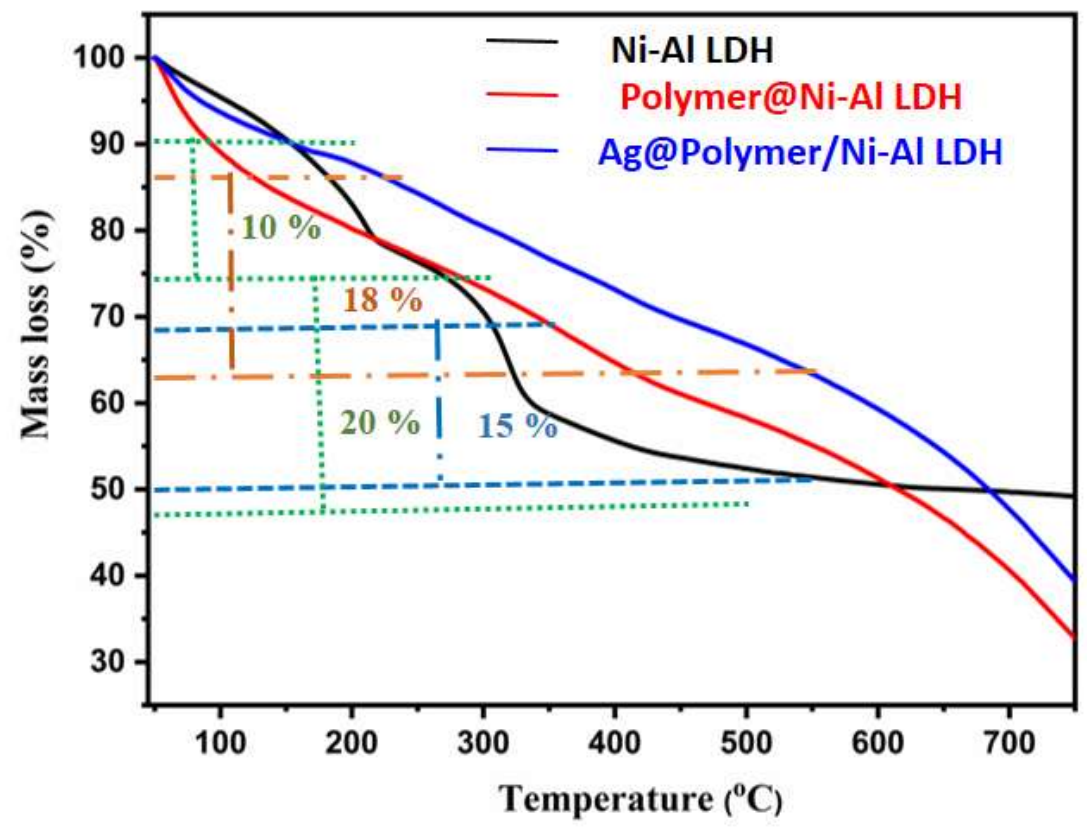

Figure S1. Thermogravimetric analysis of the as-synthesized NiAl LDH, Polymer@LDH and Ag@Polymer@LDH materials.
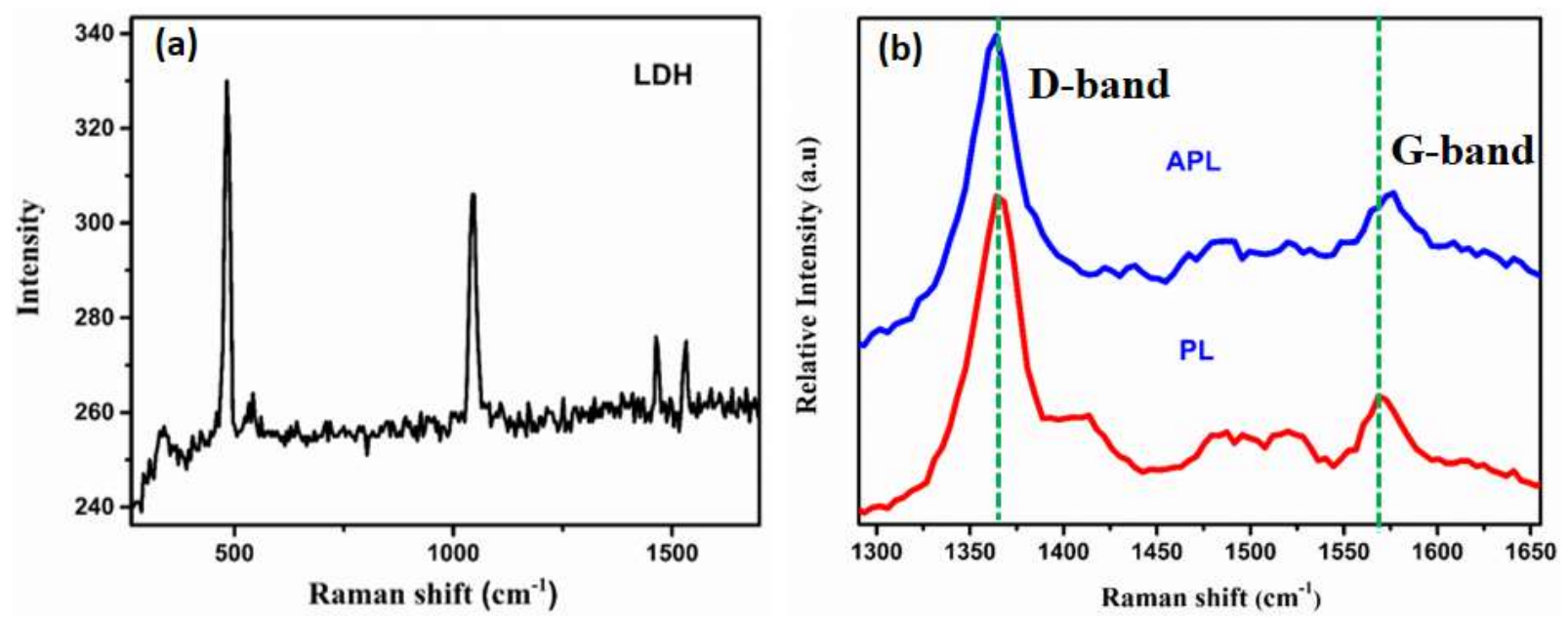

Figure S2. (a) Raman spectrum of pure LDH and (b) Raman spectra of Polymer@LDH, Ag@Polymer@LDH materials. 

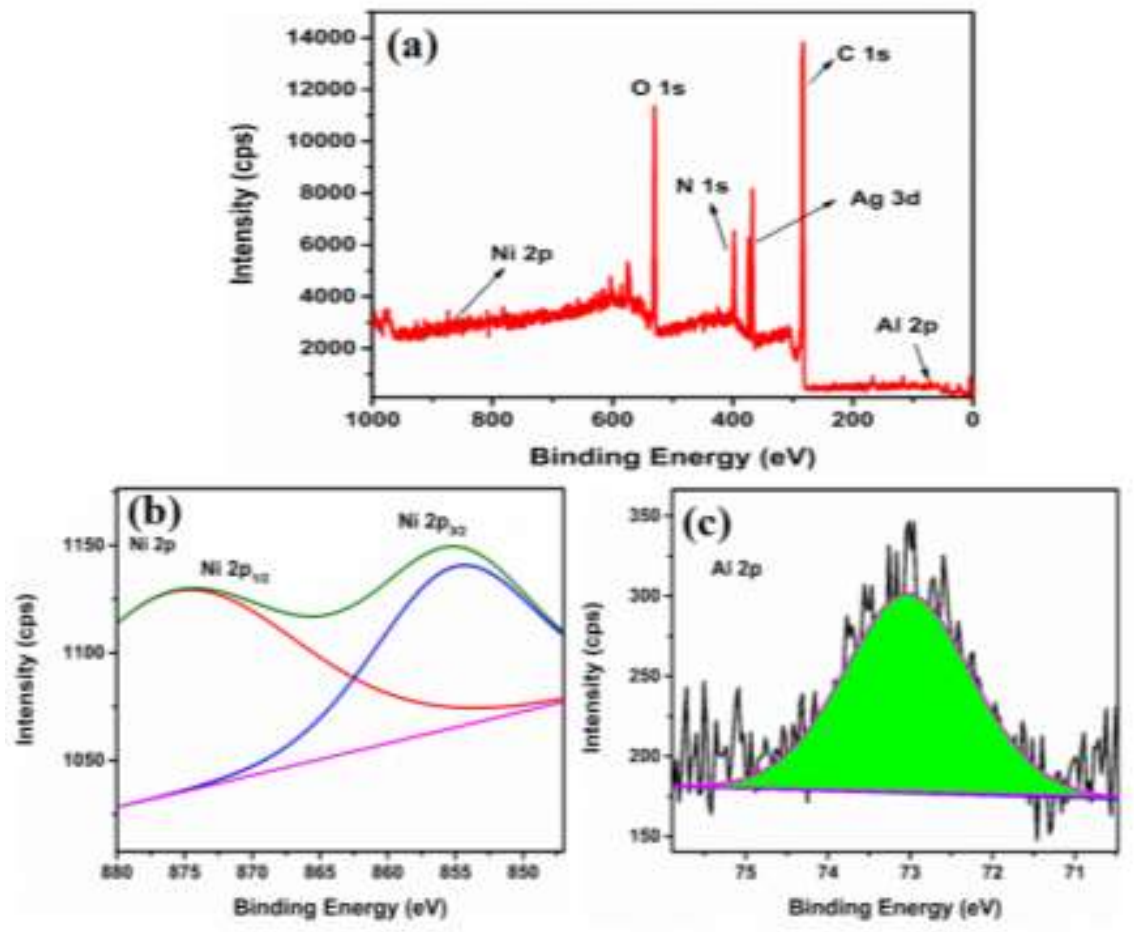

Figure S3. XPS analysis of (a) survey spectrum of Ag@Polymer@LDH, (b\&c) core level spectrum of $\mathrm{Ni}(2 \mathrm{p})$ and $\mathrm{Al}(2 \mathrm{p})$.

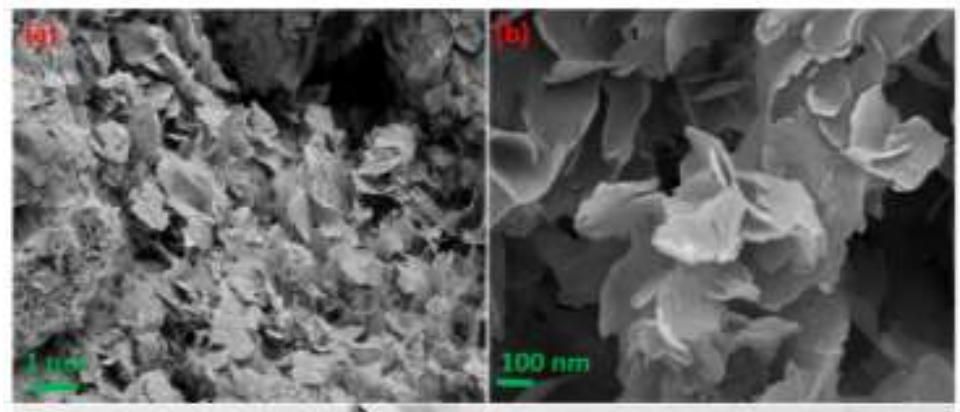

(c)

(d)

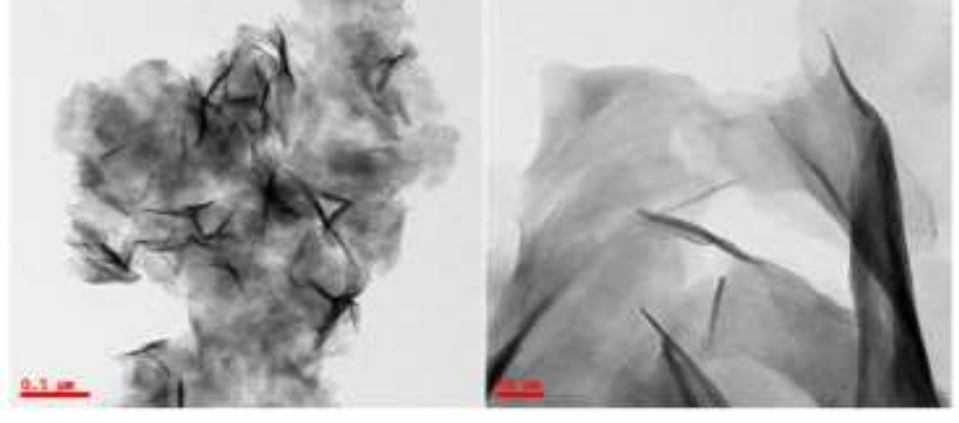

Figure S4. (a,b) FESEM images and (c, d) HRTEM images of pure layered double hydroxides. 

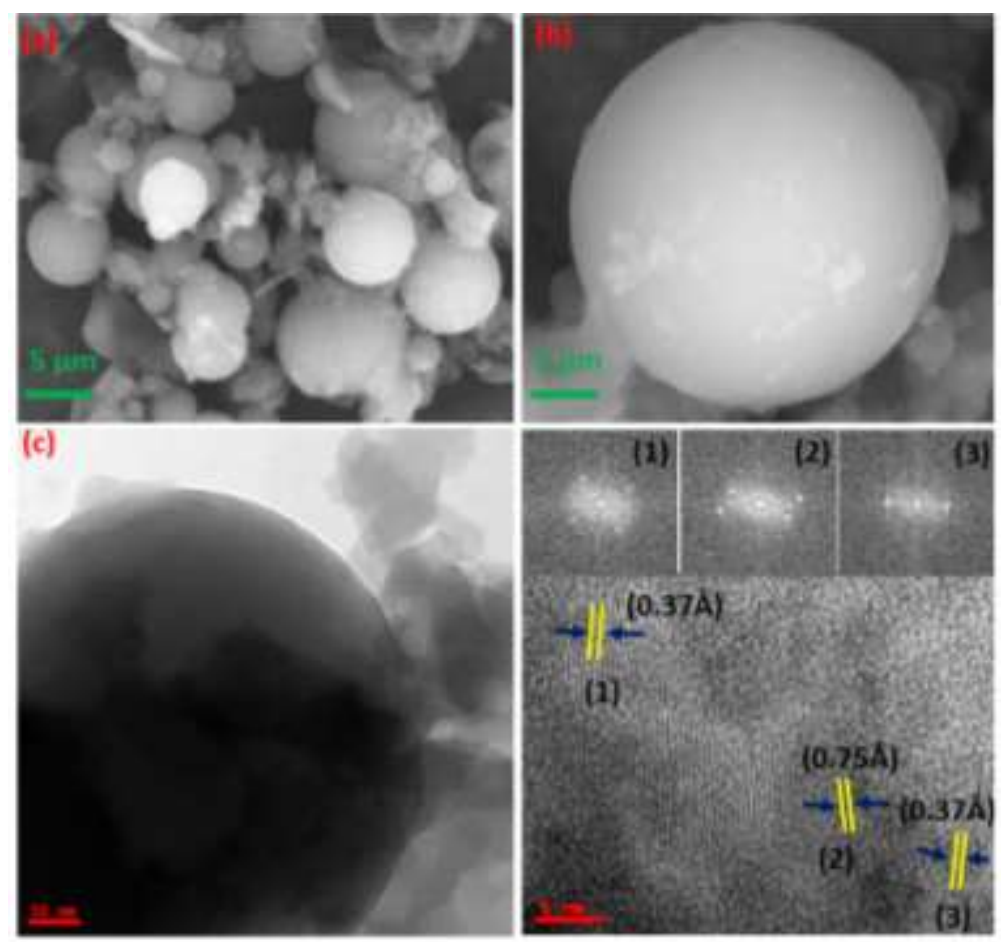

Figure S5. (a, b) FESEM images and (c, d) HRTEM images of PL and the FFT images of the Polymer@LDH represented in the inset figure of S5 (d.)

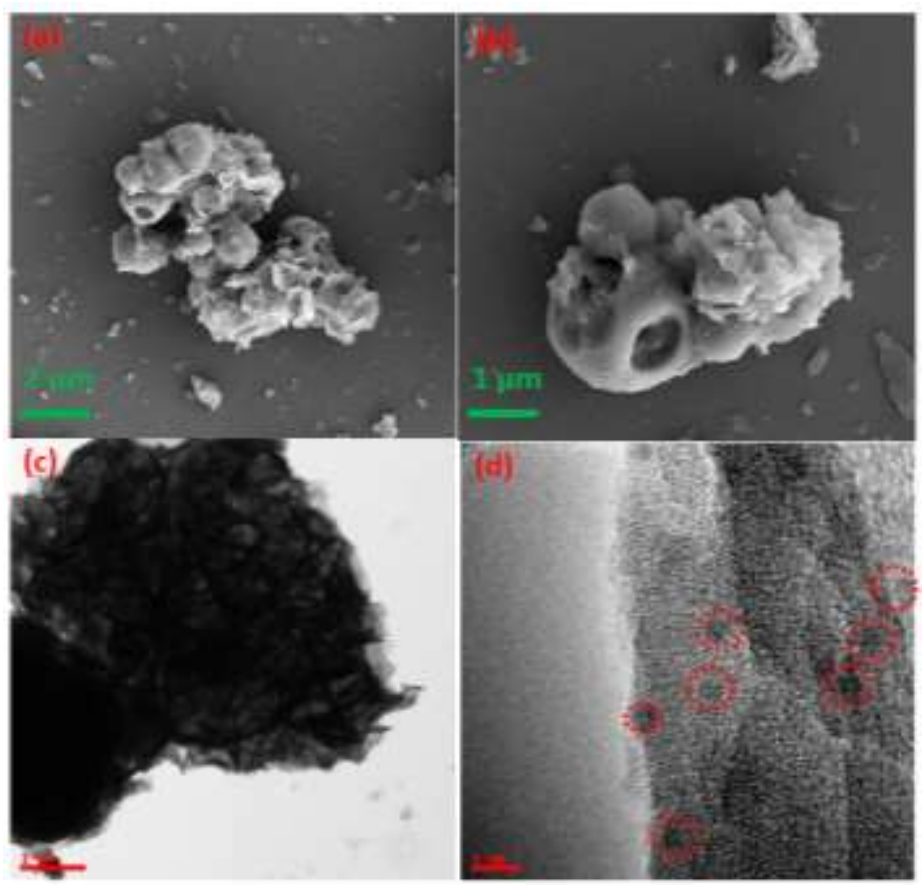

Figure S6. $(a, b)$ FESEM images and $(c, d)$ High and low magnification HRTEM images of Ag@Polymer@LDH. 

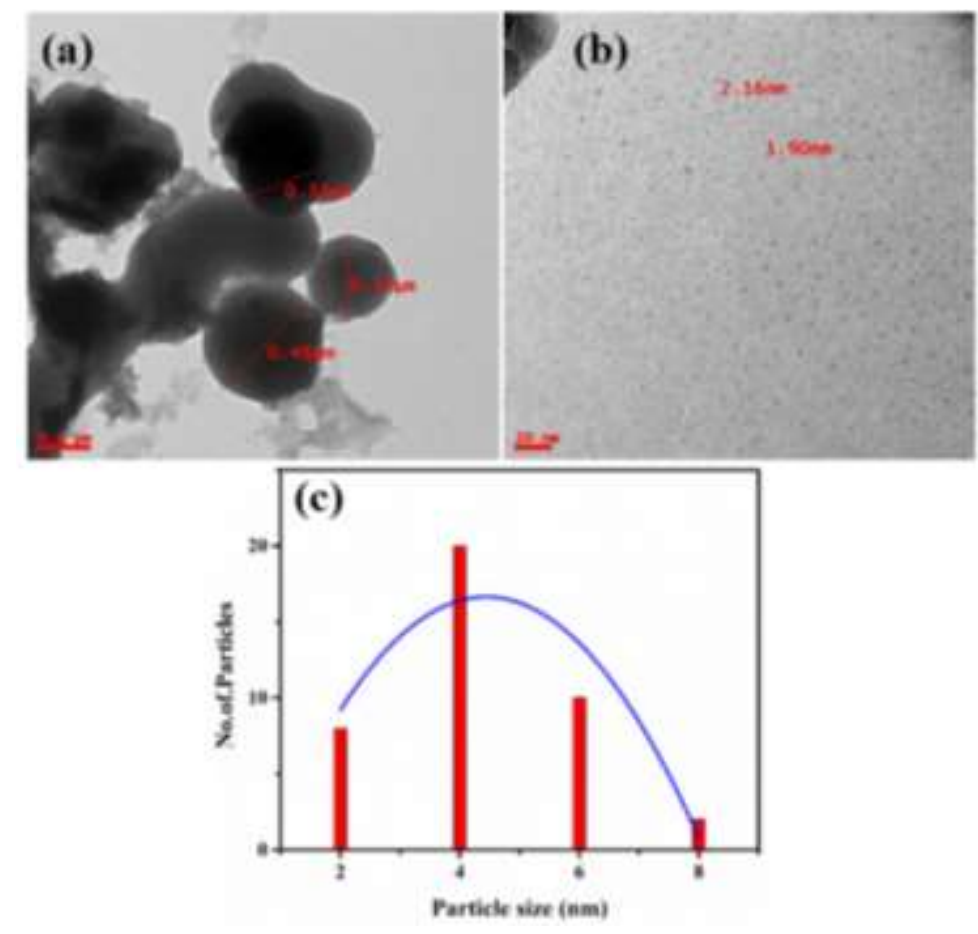

Figure S7. (a\&b) High and low HRTEM images Polymer@LDH and Ad@ polymer@LD. (c) Ag nanoparticles size distribution

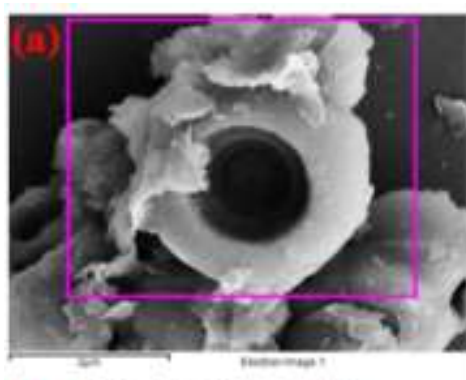

(b) Quantitative results

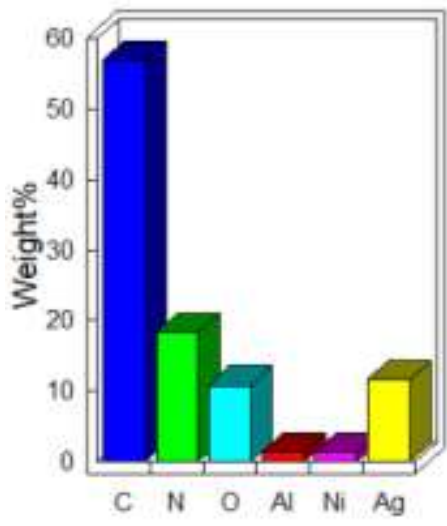

(c)

$\mathrm{Ni}$
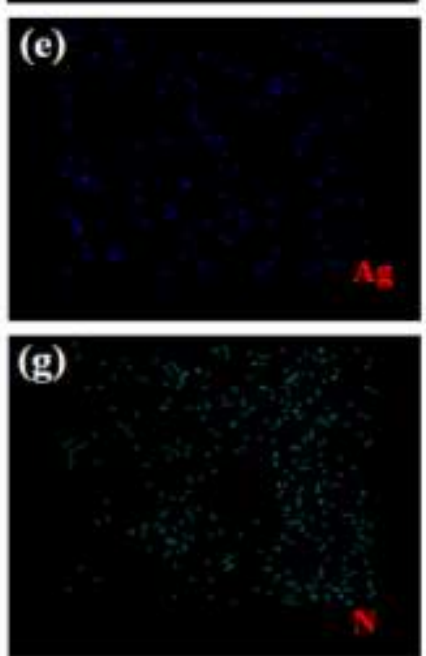

(d)

iil

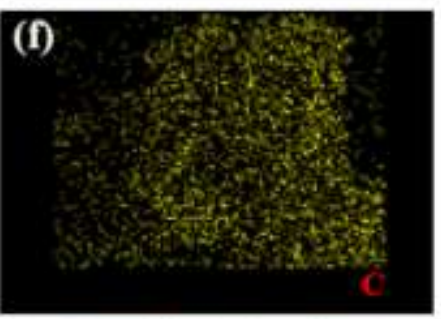

(h) 
Figure S8. (a\&c-h) Elemental mapping of the Ag@Polymer@LDH nanohybrid materials and (b) Quantitative results of Ag@Polymer@LDH

\section{Ag Concentration Effect:}

The electrochemical sensing of the 4-NP indicates that the APL nanohybrids have higher catalytic activity against the detection of 4-NP than the other modified electrodes due to the Ag support and may play an active part in the catalysis, yielding a synergistic effect. To sum of, the Ag nano structuration in terms of size, shape, and distance between the Ag NPs influences the electroreduction of 4-NP. Later, we assume that a synergetic effect between APL surfaces creates an active nanocomposite interface, which would be responsible for the electrochemical behavior of the APL electrode [3]

Figure S8 b results clearly show that in a certain range, the increase of Ag content has a significant promoting effect on the overpotential, which infers to reduce the resistance and increased the charge transfer speed. Typically high-level resistance of the materials tends to lower activity which happens to the higher amount of $\mathrm{Ag}$ present. The major pitfall is excessive $\mathrm{Ag}$ plays a negative impact on the performance of the materials. However, the excessive content of silver also leads to the increase of overpotential and Tafel plot values because the Ag itself does not have OER catalytic properties [4]. 

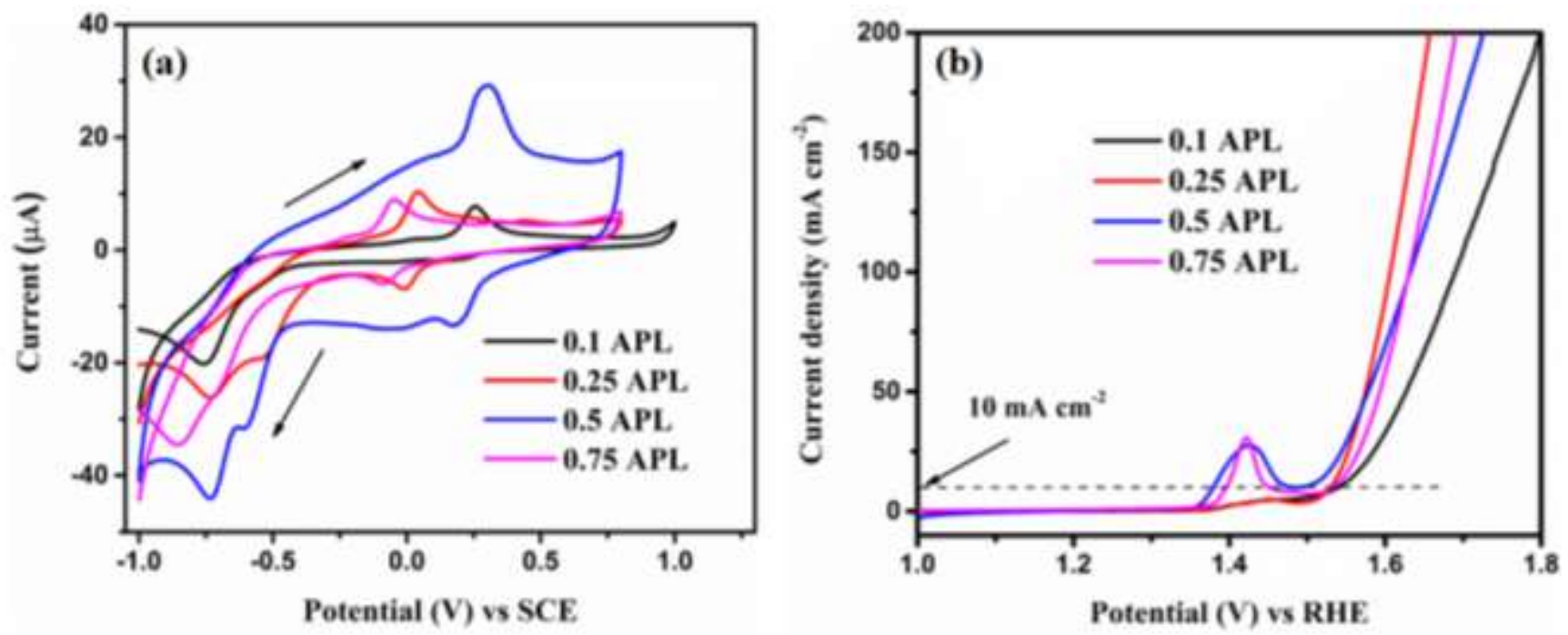

Figure S9. Preparation of different ratios of Ag contained nanohybrid materials [0.1 mmol, 0.25 $\mathrm{mmol}, 0.5 \mathrm{mmol}$ and $0.75 \mathrm{mmol}$ ] (a) Electrochemical sensing of 4-NP at a scan rate of $50 \mathrm{mV} / \mathrm{s}$ at pH-6 using Cyclic voltammetry and (b) LSV polarization curves of Oxygen Evolution Reaction at $5 \mathrm{mV} / \mathrm{s}$.

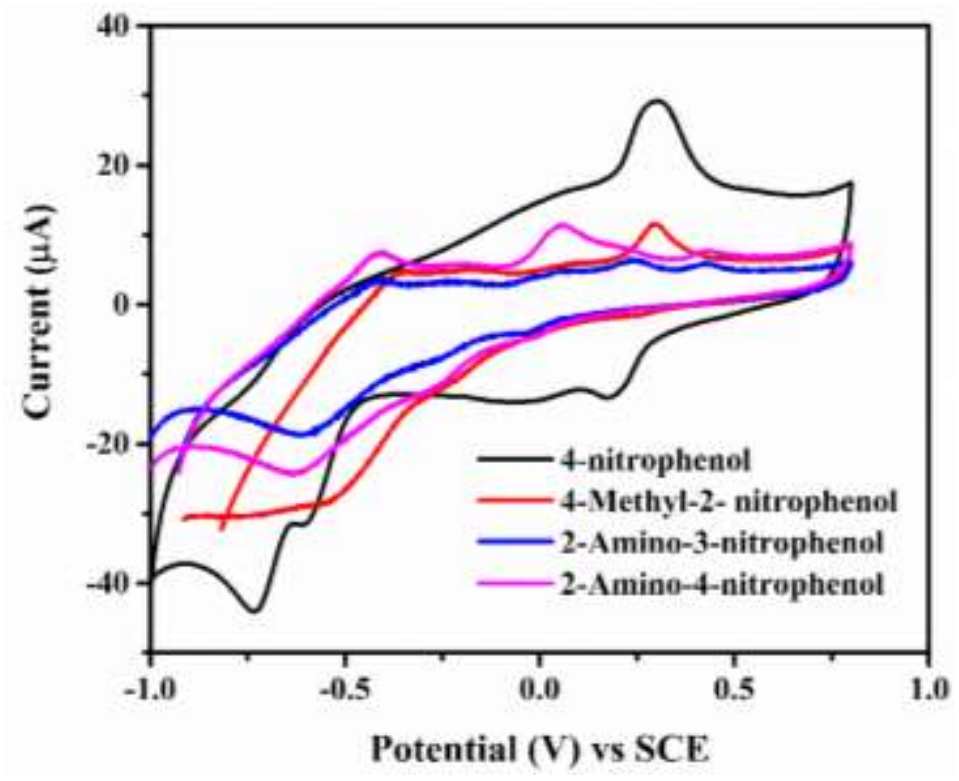

Figure S10. Cyclic voltammetry sensing of different nitrophenol compounds using APL modified electrode. 

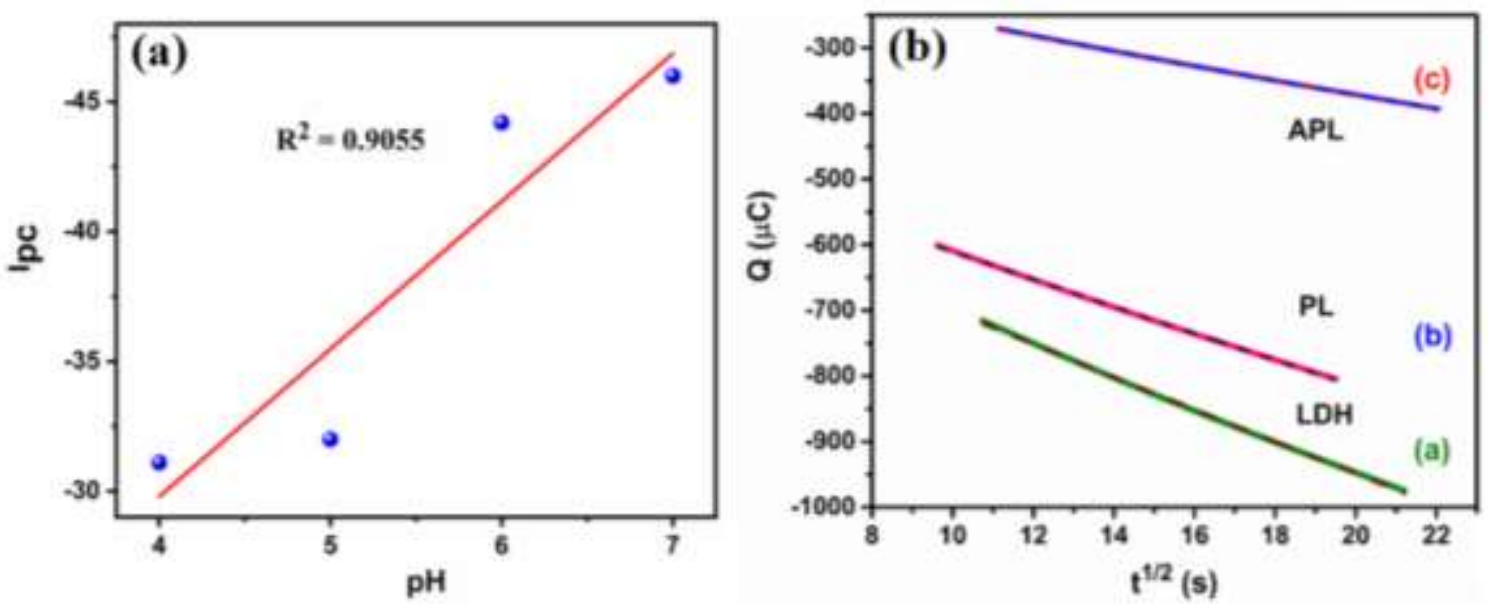

Figure S11. (a) Linear plot of $\mathrm{pH}$ vs Ipc of the $\mathrm{pH}$ effect and (b) plot of $\mathrm{t}^{1 / 2}$ vs Charge.

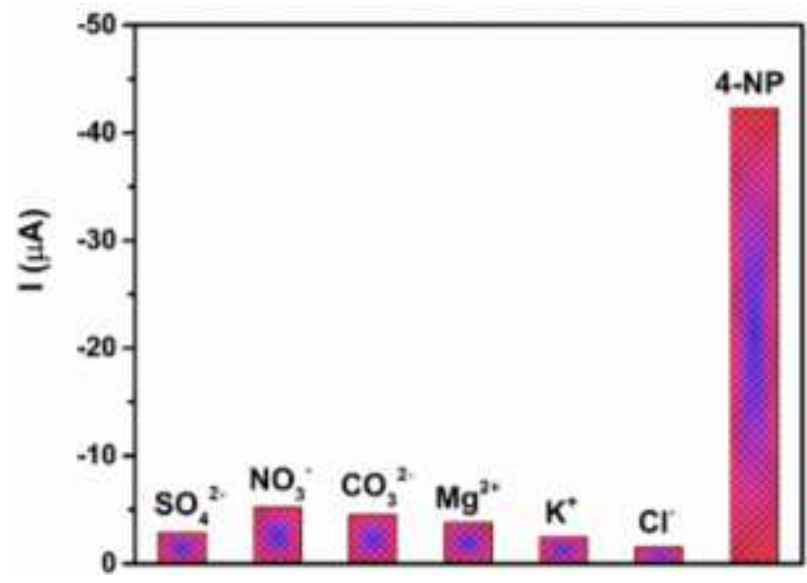

Figure S12. Selectivity study of Ag@Polymer@LDH modified electrode for 4-NP over the foremost possible interfering compounds. 

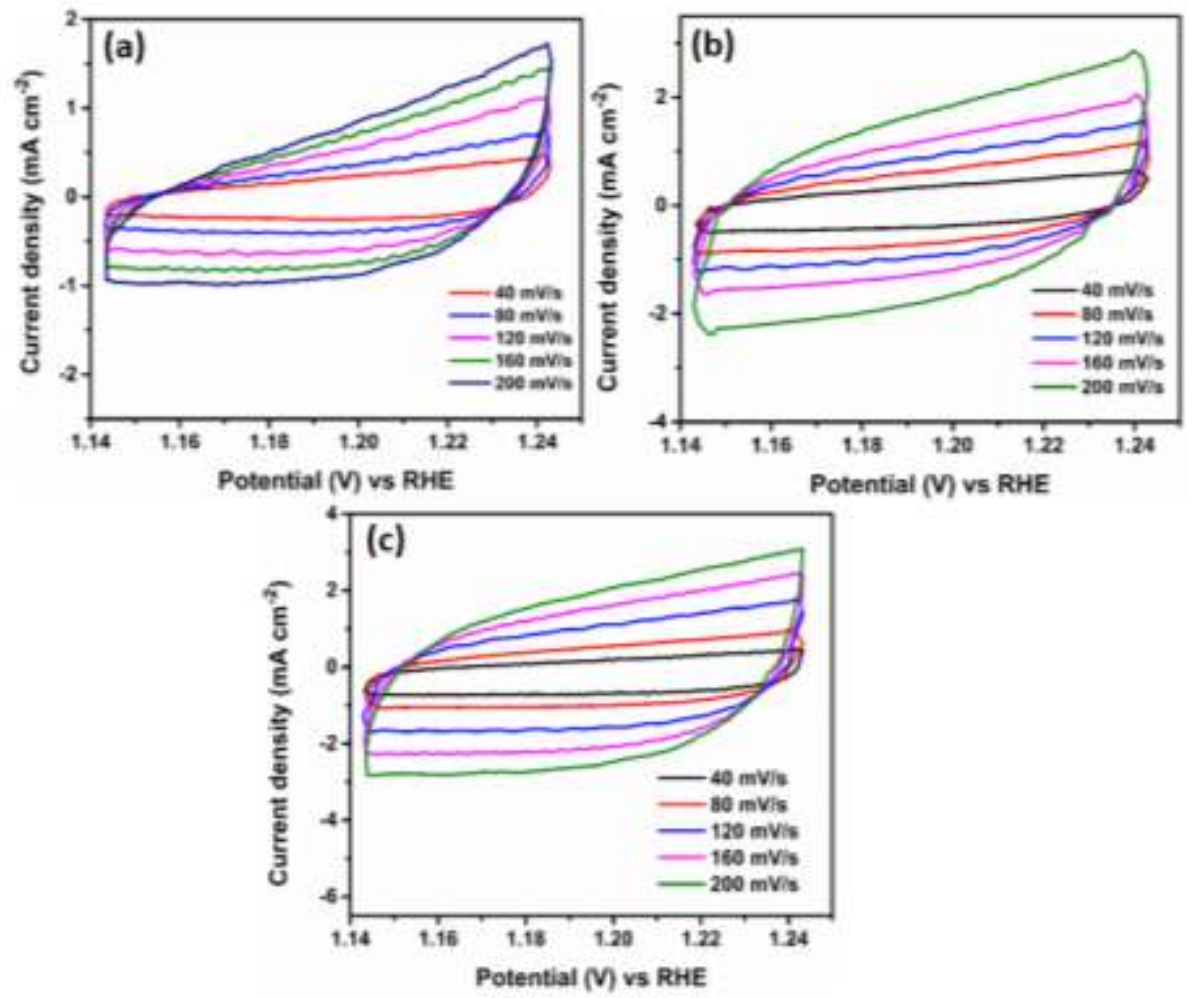

Figure S13. CV curves of the synthesized (a) Pure NiAl LDH, (b) Polymer@LDH and (c) Ag@Polymer@LDH.

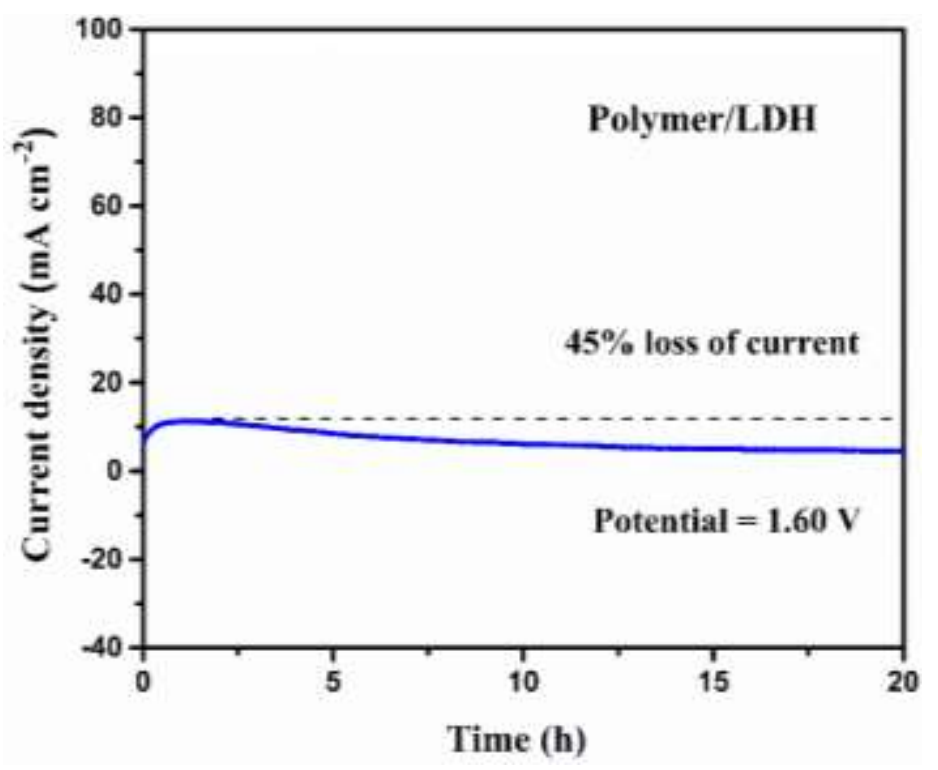

Figure S14. Long duration cyclic stability of Polymer@LDH electrode using Chronoamperometry test. 


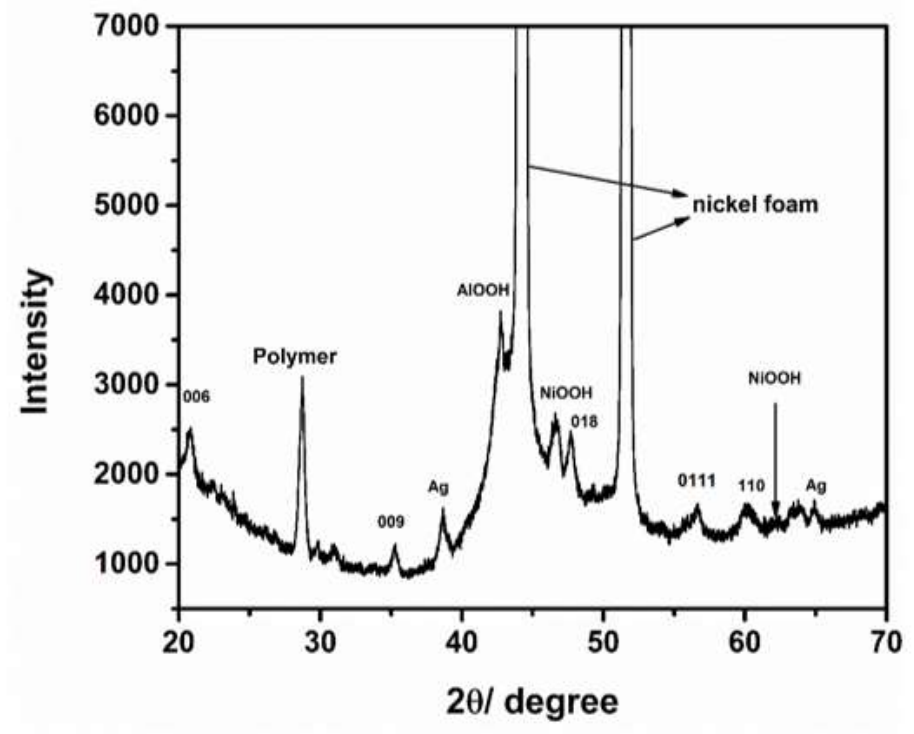

Figure S15. XRD image of post-Chronoamperometry test of APL.
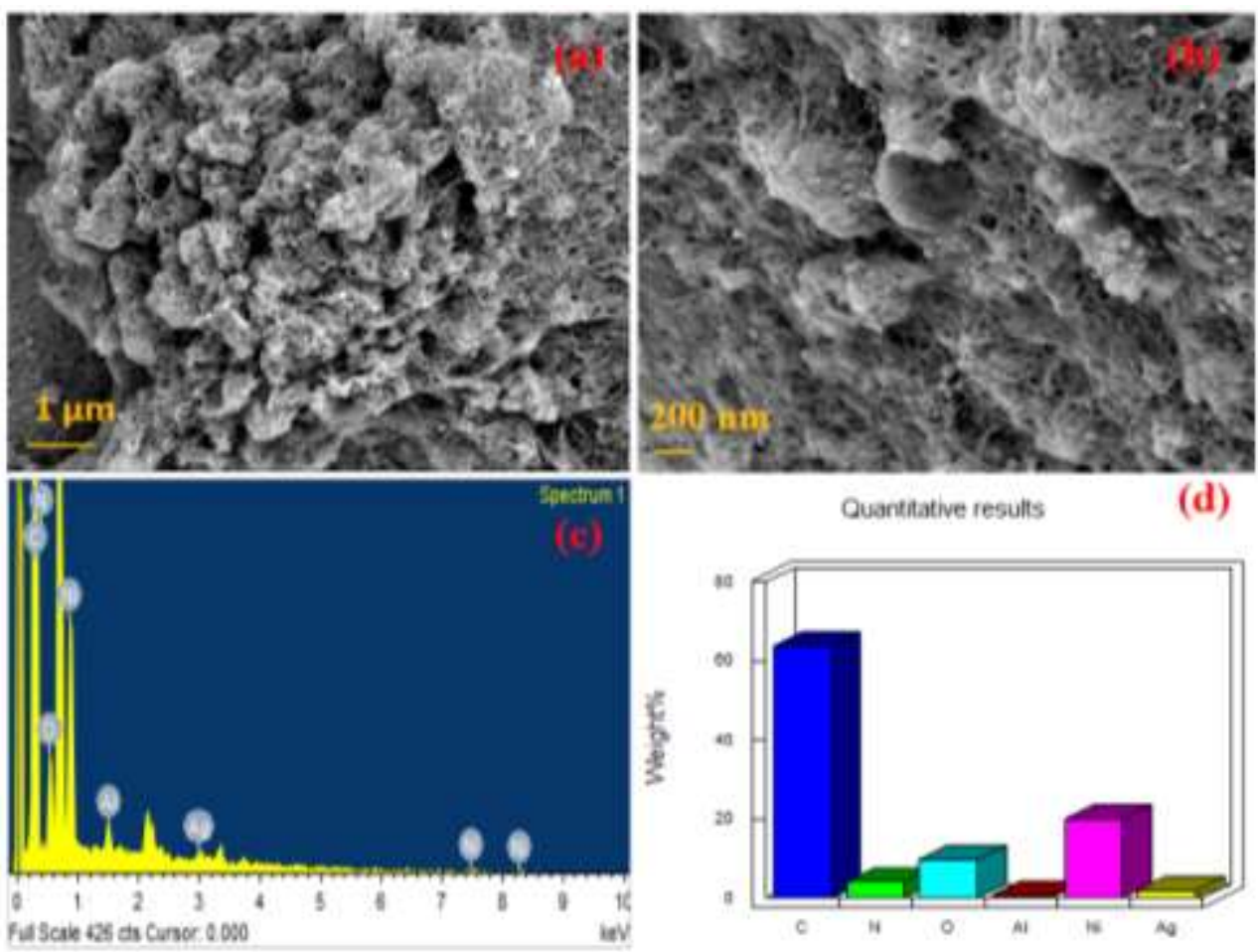

Figure S16. (a\&b) FESEM high and low magnification images after 1500 cycles of APL electrocatalysts and (c\&d) EDX spectrum and Quantitative analysis of APL electrocatalysts. 

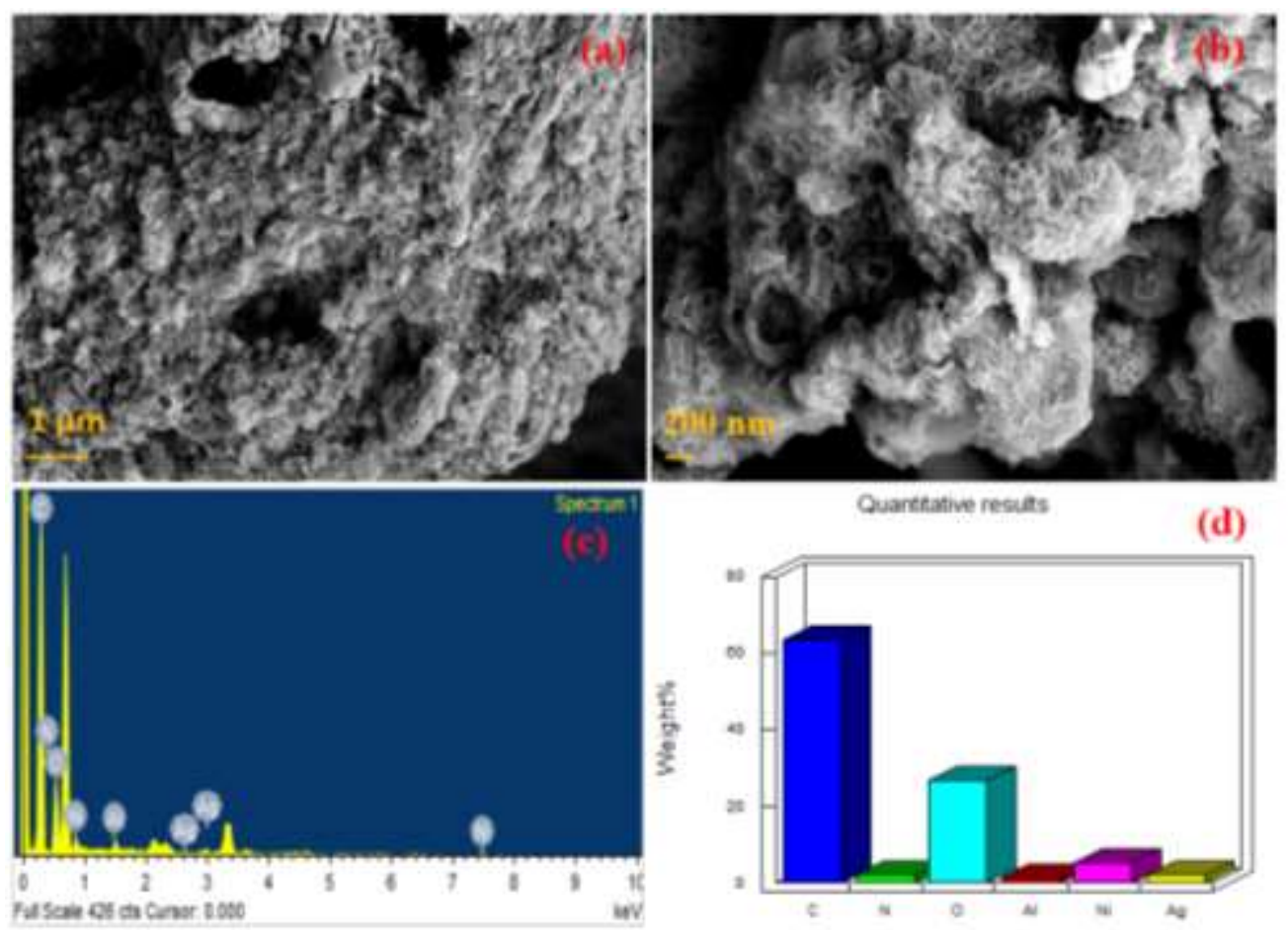

Figure S17. (a\&b) FESEM high and low magnification images of after CA test of APL electrocatalysts and (c) (c\&d) EDX spectrum and Quantitative analysis of APL electrocatalysts.
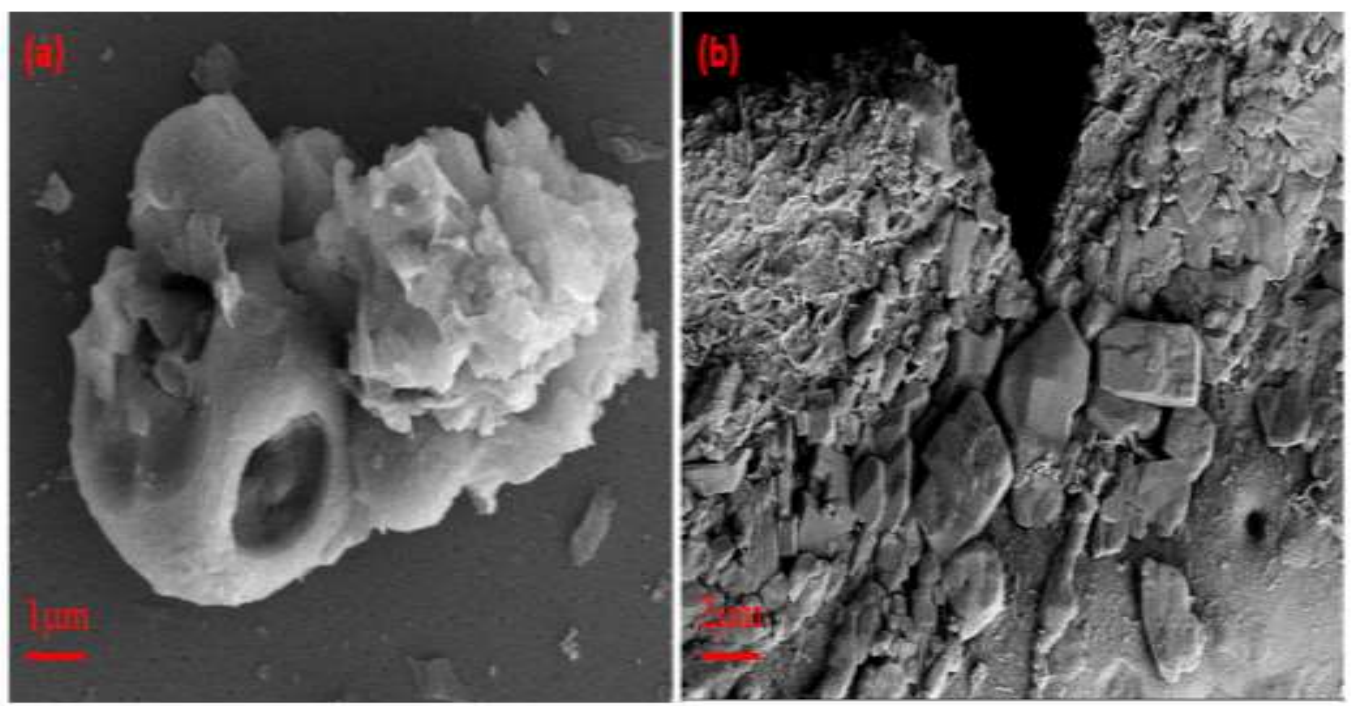

Figure S18. FESEM images of (a) before and (b) after the chronoamperometry test of Ag@Polymer@LDH electrocatalysts. 
Table S1. The atomic percentage of the elements in the Post-experiments

\begin{tabular}{|c|c|c|c|}
\hline \multirow{2}{*}{ Elements } & \multicolumn{2}{|c|}{$\begin{array}{c}\text { Atomic \% of APL electrocatalysts } \\
\text { (\%) }\end{array}$} & $\begin{array}{c}\text { Atomic \% APL } \\
\text { electrocatalysts after }\end{array}$ \\
\cline { 2 - 3 } & Before CA test & After CA test & 1500 cycles \\
\hline $\mathrm{C}$ & 82.4 & 73 & 80.63 \\
\hline $\mathrm{N}$ & 3.3 & 1.94 & 4.48 \\
\hline $\mathrm{O}$ & 10.3 & 23 & 9.10 \\
\hline $\mathrm{Ag}$ & 0.32 & 0.23 & 0.24 \\
\hline $\mathrm{Ni}$ & 3.26 & 1.25 & 5.1 \\
\hline $\mathrm{Al}$ & 0.58 & 0.52 & 0.37 \\
\hline
\end{tabular}

Table S2. Cyclic voltammetry redox values of the modified electrocatalysts

\begin{tabular}{|c|c|c|c|c|}
\hline Catalysts & Ipa $(\mu \mathrm{A})$ & Ipc $(\mathrm{mV})$ & Epa $(m V)$ & Epc (mV) \\
\hline Bare GCE & --- & --- & --- & --- \\
\hline APL & 6.09 & -11.82 & 0.425 & -0.465 \\
\hline $\mathrm{LDH}+4-\mathrm{NP}$ & $1.96,7.85$ & -20.36 & $0.029,0.257$ & -0.75 \\
\hline $\mathrm{PL}+4-\mathrm{NP}$ & $\begin{array}{l}15.0, \quad 24.39, \\
26.91,15.49\end{array}$ & $-15.53,-50.16$ & $\begin{array}{l}-0.09, \quad 0.11, \\
0.19,0.47\end{array}$ & $0.04,-0.83$ \\
\hline APL+4-NP & $16.0,29.6$ & $\begin{array}{l}-12.8,-31.69 \\
-44.3\end{array}$ & $0.07,0.30$ & $\begin{array}{l}0.17,-0.60, \\
-0.73\end{array}$ \\
\hline
\end{tabular}


Table S3. Comparative limit of the detection value of different electrocatalysts for 4-NP sensing.

\begin{tabular}{|c|c|c|c|c|c|}
\hline Catalysts & $\begin{array}{l}\text { Linear range } \\
\qquad(\mu \mathrm{M} / \mathbf{n M})\end{array}$ & $\begin{array}{c}\text { Sensitivity } \\
\left(\mu \mathrm{A} \mu \mathrm{M}^{-1} \mathrm{~cm}^{-2}\right)\end{array}$ & $\begin{array}{l}\text { LOD } \\
(\mu \mathrm{M})\end{array}$ & Method & Ref. \\
\hline $\mathrm{NiFe}_{2} \mathrm{O}_{4}-\mathrm{rGO} 10 / \mathrm{GCE}$ & $0.5-4000 \mu \mathrm{M}$ & 1.80 & 0.045 & SWASV & 5 \\
\hline $\mathrm{CeO}_{2}-\mathrm{ZnO} \mathrm{NEs}$ & $(100-1000 \mathrm{nM}$ & 0.120 & 1.163 & Amp & 6 \\
\hline AgNWs-PANI & $0.6-32$ & --- & 0.052 & DPV & 7 \\
\hline $\begin{array}{l}\mathrm{CPE}-\alpha-\mathrm{Fe}_{2} \mathrm{O}_{3} @ \mathrm{Mg} / \mathrm{Al}- \\
\mathrm{CO}_{3}{ }^{-} \mathrm{LDH}\end{array}$ & --- & --- & 4.98 & SWV & 8 \\
\hline $\mathrm{Au}$ NPs on $\mathrm{Au}$ electrode & $\begin{array}{c}0.1 \mu \mathrm{M} \text { to } 1.4 \\
\mathrm{mM}\end{array}$ & --- & 0.1 & DPV & 9 \\
\hline $\mathrm{ZnBi}_{38} \mathrm{O}_{60}$ & 0.6 to $8.33 \mu \mathrm{M}$ & 1.024 & $\begin{array}{c}0.035 \\
\mathrm{~nm}\end{array}$ & DPV & 10 \\
\hline APL & $10-100$ & 6.542 & 0.0096 & DPV & $* * *$ \\
\hline
\end{tabular}

LOD-Limit of detection, SWASV-Square wave anodic stripping voltammetry, Amp- Amperometry, DPV-Differential pulse voltammetry, ***- This work.

Table S4. EIS values of different electrocatalysts on nickel foam substrate for OER

\begin{tabular}{|c|c|c|c|}
\hline Catalysts & $\mathbf{R}_{\mathbf{s}}(\mathbf{\Omega})$ & $\mathbf{R}_{\mathbf{c t 1}}(\mathbf{\Omega})$ & $\mathbf{R}_{\mathbf{c t 2}}(\mathbf{\Omega})$ \\
\hline $\mathrm{APL}$ & 0.92 & 0.05 & 29.56 \\
\hline $\mathrm{RuO}_{2}$ & 0.97 & 0.06 & 39.37 \\
\hline $\mathrm{PL}$ & 1.61 & 0.14 & 105.2 \\
\hline $\mathrm{LDH}$ & 1.97 & 0.25 & 157.0 \\
\hline
\end{tabular}


Table S5. Oxygen evolution reaction at different overpotentials using the as synthesized materials

\begin{tabular}{|c|c|c|c|c|}
\hline Overpotentials ( $\boldsymbol{\eta})$ & Ni-Al LDH & Polymer@LDH & Ag@Polymer@LDH & RuO $_{2}$ \\
\hline $10 \mathrm{~mA} \mathrm{~cm}^{-2}$ & 318 & 306 & $\mathbf{2 5 9}$ & 303 \\
\hline $50 \mathrm{~mA} \mathrm{~cm}^{2}{ }^{2}$ & 442 & 386 & $\mathbf{3 4 5}$ & 365 \\
\hline $100 \mathrm{~mA} \mathrm{~cm}^{2}$ & 565 & 435 & $\mathbf{4 0 1}$ & 400 \\
\hline
\end{tabular}

Table S6. Summarized low overpotential of the different electrocatalysts for OER.

\begin{tabular}{|c|c|c|c|c|c|c|}
\hline Catalysts & Substrate & $\begin{array}{c}\text { (j) } \mathbf{m A} \mathbf{A} \\
\mathbf{c m}^{-2}\end{array}$ & $\begin{array}{l}\text { (n) in } \\
\mathrm{mV}\end{array}$ & $\begin{array}{c}\text { Stability } \\
\text { test }\end{array}$ & Electrolyte & Ref \\
\hline $\begin{array}{l}\text { Ni@Pt core-shell } \\
\text { NPs }\end{array}$ & GCE & 10 & 290 & $\begin{array}{c}\mathrm{CA} @ 10 \\
\mathrm{~h}\end{array}$ & $1 \mathrm{M} \mathrm{KOH}$ & 11 \\
\hline $\begin{array}{l}\mathrm{NiCo}_{2} \mathrm{~S}_{4} @ \mathrm{Co}_{1} \mathrm{Ni}_{4}- \\
\mathrm{LDH}\end{array}$ & $\mathrm{CC}$ & 100 & 337 & $\begin{array}{l}\mathrm{CP} @ 20 \\
\mathrm{~mA} \mathrm{~cm}{ }^{-2}\end{array}$ & $1 \mathrm{M} \mathrm{KOH}$ & 12 \\
\hline $\mathrm{S}-\mathrm{NiFe}_{2} \mathrm{O}_{4} / \mathrm{NF}$ & NF & 10 & 267 & $\begin{array}{c}\mathrm{CA} @ 24 \\
\mathrm{~h}\end{array}$ & $1 \mathrm{M} \mathrm{KOH}$ & 13 \\
\hline NiCo-LDH@HOS & NF & 10 & 293 & $\begin{array}{c}\mathrm{CA} @ 62 \\
\mathrm{~h}\end{array}$ & $\begin{array}{l}0.1 \mathrm{M} \\
\mathrm{KOH}\end{array}$ & 14 \\
\hline $\begin{array}{l}\text { Ni-Fe LDH } \\
\text { DSNCs }\end{array}$ & $\mathrm{CP}$ & 20 & 246 & CA@6h & $1 \mathrm{M} \mathrm{KOH}$ & 15 \\
\hline $\begin{array}{l}\mathrm{Ni}_{3} \mathrm{~S}_{2} @ \mathrm{NiV}- \\
\mathrm{LDH} / \mathrm{NF}\end{array}$ & NF & 10 & 320 & CA @ 100 & $1 \mathrm{M} \mathrm{KOH}$ & 16 \\
\hline $\begin{array}{l}\mathrm{Ni}-\mathrm{Co} \quad \mathrm{LDH} / \mathrm{Ni}- \\
\mathrm{Mo}-\mathrm{S}\end{array}$ & NF & 40 & 290 & $\begin{array}{c}\text { CA@ @ } 14 \\
\text { h }\end{array}$ & $1 \mathrm{M} \mathrm{KOH}$ & 17 \\
\hline $\mathrm{NiCoFexP/CC}$ & $\mathrm{CC}$ & 50 & 275 & $\begin{array}{l}\mathrm{CP} @ 100 \\
\mathrm{~mA} \mathrm{~cm}{ }^{-2}\end{array}$ & $1 \mathrm{M} \mathrm{KOH}$ & 18 \\
\hline $\begin{array}{l}\text { NisMn- } \\
\text { LDH/MWCNT }\end{array}$ & NF & 10 & 350 & $\begin{array}{l}\mathrm{CP} @ 10 \\
\mathrm{~mA} \mathrm{~cm}{ }^{-2}\end{array}$ & $1 \mathrm{M} \mathrm{KOH}$ & 19 \\
\hline APL & NF & 10 & 259 & $\underset{h}{C A @ 36}$ & $1 \mathrm{M} \mathrm{КОН}$ & $* * *$ \\
\hline
\end{tabular}

GCE-Glassy carbon electrode; CC- Carbon cloth; NF-Nickel foam; CP-Carbon paper; CAChronoamperometry; CP-Chronopotentiometry; ***- This work.

\section{Reference}

1. Zhang, Y. S., Xu, W. H., Yao, W. T., \& Yu, S. H. Oxidation- reduction reaction driven approach for hydrothermal synthesis of polyaniline hollow spheres with controllable size and shell thickness. J. Phy. Chem. C, 2009, 113, 8588-8594. 
2. Andriianova, A. N., Biglova, Y. N., \& Mustafin, A. G. Effect of structural factors on the physicochemical properties of functionalized polyanilines. $R S C A d v, \mathbf{2 0 2 0}, 10,7468$ 7491.

3. Schulte, M. F., Scotti, A., Brugnoni, M., Bochenek, S., Mourran, A., \& Richtering, W. Tuning the Structure and Properties of Ultra-Low Cross-Linked Temperature-Sensitive Microgels at Interfaces via the Adsorption Pathway. Langmuir, 2019, 35(46), 1476914781.

4. Dong, R., Du, H., Sun, Y., Huang, K., Li, W., \& Geng, B. Selective Reduction-Oxidation Strategy to the Conductivity-Enhancing Ag-Decorated Co-Based 2D Hydroxides as Efficient Electrocatalyst in Oxygen Evolution Reaction. ACS Sustain. Chem. Eng, 2018, 6, 13420-13426.

5. Komal, R.; Kaur, R.; Kaur, J.; Jyoti.; Kumar, V.; Tikoo, K. B.; Rana, S.; Kaushik, A.; Singhal, S. Unfolding the electrocatalytic efficacy of highly conducting $\mathrm{NiFe}_{2} \mathrm{O}_{4}-\mathrm{rGO}$ nanocomposites on the road to rapid and sensitive detection of hazardous p-Nitrophenol. J. Electroanal. Chem., 2021, 887, 115161.

6. Singha, K. Ibrahim, Ahmed. I.; Umar, A.; Kumar, A.; Chaudhary, G. R.; Singh, S.; Mehta. S. K.; Synthesis of $\mathrm{CeO}_{2}-\mathrm{ZnO}$ nanoellipsoids as potential scaffold for the efficient detection of 4-nitrophenol. Sens and actuators B: Chemical.2014, 202, 1044-1050.

7. Zhang, C.; Govindaraju, S.; Giribabu, K.; Huh Y. S; Yun, K.; AgNWs-PANI nanocomposite based electrochemical sensor for detection of 4-nitrophenol. Sens and actuators B: Chemical. 2017, 252, 616-623.

8. Dib, M.; Moutcine, A.; Ouchetto, H.; Ouchetto, K.; Chtaini, A.; Hafid, A.; Khouilia, M.; Novel synthesis of $\alpha-\mathrm{Fe}_{2} \mathrm{O}_{3} @ \mathrm{Mg} / \mathrm{Al}-\mathrm{CO}_{3}{ }^{-} \mathrm{LDH}$ nanocomposite for rapid electrochemical detection of p-nitrophenol. Inorg. Chem. Commun., 2021, 21, 108788.

9. Xu, G.; Yang, L.; Zhong, M.; Li, C.; Lu, X.; Kan, X.; Selective recognition and electrochemical detection of $\mathrm{p}$-nitrophenol based on a macroporous imprinted polymer containing gold nanoparticles. Microchim Acta. 2013, 180, 1461-1469.

10. Padmanaban, A.; Dhanasekaran, T.; Manigandan, R.; Praveen Kumar, S.; Gnanamoorthy, G.; Stephen A.; Narayanan, V. Facile solvothermal decomposition synthesis of single phase $\mathrm{ZnBi}_{38} \mathrm{O}_{60}$ nanobundles for sensitive detection of 4-nitrophenol. New J. Chem., 2017, 41, 7020-7027.

11. Wang, F. Chen, G.; Liu, X.; Chen, F.; Wan, H.; Ni, L.; Zhang, N.; Ma, R.; Qiu. G. Advanced Electrocatalytic Performance of Ni-Based Materials for Oxygen Evolution Reaction. ACS Sustainable Chem. Eng. 2019, 7, 341-349.

12. Yuan, F.; Wei, J.; Qin, G.; Ni. Y. Carbon cloth supported hierarchical core-shell $\mathrm{NiCo}_{2} \mathrm{~S}_{4} @ \mathrm{CoNi}-\mathrm{LDH}$ nanoarrays as catalysts for efficient oxygen evolution reaction in alkaline solution. J. Alloys Compds. 2020, 830, 154658.

13. Liu, J.; Zhu, D.; Ling, T.; Vasileffa, A.; Qiao, S. Z. S-NiFe ${ }_{2} \mathrm{O}_{4}$ ultra-small nanoparticle built nanosheets for efficient water splitting in alkaline and neutral pH. Nano Energy 2017, 40, 264-273.

14. Xiang, K.; Guo, J.; Xu, J.; Qu, T.; Zhang, Y.; Chen, S.; Hao, P.; Li, M.; Xie, M.; Guo, X.; Ding, W. Surface Sulfurization of NiCo-Layered Double Hydroxide Nanosheets Enable 
Superior and Durable Oxygen Evolution Electrocatalysis. ACS Appl. Energy Mater. 2018, 1, 4040-4049.

15. Yu, L.; Yang, J. F.; Guan, B. Y.; Lu, Y.; Lou, X. W. (David). Hierarchical Hollow Nanoprisms Based on Ultrathin Ni-Fe Layered Double Hydroxide Nanosheets with Enhanced Electrocatalytic Activity towards Oxygen Evolution. Angew. Chem. 2018, 130, $178-182$.

16. Liu, Q.; Huang, J.; Zhao, Y.; Cao, L.; Li, K.; Zhang, N.; Yang, D.; Feng, L. Tuning the coupling interface of ultrathin $\mathrm{Ni}_{3} \mathrm{~S}_{2} @ \mathrm{NiV}-\mathrm{LDH}$ heterogeneous nanosheet electrocatalysts for improved overall water splitting. Nanoscale, 2019, 11, 8855-8863.

17. Wang, H.; Zhang, X. Ni-Co LDH/M-Mo-S ( $\mathrm{M}=\mathrm{Zn}$, Co and Ni) nanoarrays as efficient water oxidation electrocatalytic materials. CrystEngComm, 2021, 23, 2862-2868.

18. Ray, C.; Lee, S. C.; Jin, B.; Kundu, A.; Park, J. H.; Jun, S. C. Stacked Porous Iron-Doped Nickel Cobalt Phosphide Nanoparticle: An Efficient and Stable Water Splitting Electrocatalyst. ACS Sustainable Chem. Eng. 2018, 6, 6146-6156.

19. Jia, G.; Hu, Y.; Qian, Q.; Yao, Y.; Zhang, S.; Li, Z.; Zou, Z. Formation of Hierarchical Structure Composed of $(\mathrm{Co} / \mathrm{Ni}) \mathrm{Mn}-\mathrm{LDH}$ Nanosheets on MWCNT Backbones for Efficient Electrocatalytic Water Oxidation. ACS Appl. Mater. Interfaces 2016, 8, 1452714534. 